\title{
Head and neck cancer patients' preferences for individualized prognostic information: a focus group study
}

Arta Hoesseini* D, Emilie A. C. Dronkers, Aniel Sewnaik, Jose A. U. Hardillo, Robert J. Baatenburg de Jong and Marinella P. J. Offerman

\begin{abstract}
Background: Head and Neck cancer (HNC) is characterized by significant mortality and morbidity. Treatment is often invasive and interferes with vital functions, resulting in a delicate balance between survival benefit and deterioration in quality of life (QoL). Therefore, including prognostic information during patient counseling can be of great importance. The first aim of this study was to explore HNC patients' preferences for receiving prognostic information: both qualitative (general terms like "curable cancer"), and quantitative information (numbers, percentages). The second aim of this study was to explore patients' views on "OncologlQ", a prognostic model developed to estimate overall survival in newly diagnosed HNC patients.

Methods: We conducted a single center qualitative study by organizing five focus groups with HNC patients $(n=21)$ and their caregivers $(n=19)$, categorized in: 1$)$ small laryngeal carcinomas treated with radiotherapy or laser, 2) extensive oral cavity procedures, 3) total laryngectomy, 4) chemoradiation, 5) other treatments. The patients' perspective was the main focus. The interview guide consisted of two main topics: life-expectancy and the prognostic model OncologIQ. All focus groups were recorded, transcribed and coded. Themes were derived using content analysis.

Results: While all patients considered it somewhat to very important to receive information about their lifeexpectancy, only some of them wanted to receive quantitative information. Disclosing qualitative prognostic information like "the cancer is curable" would give enough reassurance for most patients. Overall, patients thought life-expectancy should not be discussed shortly after cancer diagnosis disclosure, as a certain time is needed to process the first shock. They had a stronger preference for receiving prognostic information in case of a poor prognosis. Prognostic information should also include information on the expected QoL. The pie chart was the most preferred chart for discussing survival rates.

Conclusions: The participants found it important to receive information on their life-expectancy. While most patients were enough reassured by qualitative prognostic information, some wanted to receive quantitative information like OncologlQs' estimates. A tailor-made approach is necessary to provide customized prognostic information. A clinical practice guideline was developed to support professionals in sharing prognostic information, aiming to improve shared decision making and patient-centered care.
\end{abstract}

Keywords: Prognosis, Life expectancy, Head and neck cancer, Focus groups, Qualitative research, Quality of life, Survival, Communication, Patient-centered care, Shared decision making

\footnotetext{
* Correspondence: a.hoesseini@erasmusmc.nl

Department of Otorhinolaryngology and Head and Neck Surgery, Erasmus

MC Cancer Institute, Erasmus University Medical Center, Dr. Molewaterplein

40, 3015, GD, Rotterdam, The Netherlands
}

(c) The Author(s). 2020 Open Access This article is distributed under the terms of the Creative Commons Attribution 4.0 International License (http://creativecommons.org/licenses/by/4.0/), which permits unrestricted use, distribution, and reproduction in any medium, provided you give appropriate credit to the original author(s) and the source, provide a link to the Creative Commons license, and indicate if changes were made. The Creative Commons Public Domain Dedication waiver (http://creativecommons.org/publicdomain/zero/1.0/) applies to the data made available in this article, unless otherwise stated. 


\section{Background}

Head and Neck cancer (HNC) is an aggressive type of cancer characterized by significant mortality and morbidity [1-4]. Treatment is often invasive and interferes with vital functions such as breathing, swallowing, and speech. In addition, patients often face psychosocial problems and experience body image dissatisfaction as a result of the mutilating procedures $[2,5]$. On the one hand physicians aim for cure and prolonging life, while on the other hand they strive for optimization of quality of life (QoL). This often results in a delicate balance between survival benefit and the functional, and psychosocial disabilities a patient is willing to accept after treatment. Therefore adequate counseling of patients including prognostic information can be of great importance. Previous research focused on whether or not to disclose the prognosis [6]. More recently the focus has shifted more in-depth to what information to provide, and how to do this [6-8]. This is in line with the increased attention for shared decision making (SDM). Patients need to be well-informed before they can be actively involved in treatment decisions [9, 10]. As patients may not be able to make well-informed treatment decisions without understanding their prognosis, providing prognostic information is a key factor in SDM.

We recently published the results of a qualitative research, focusing on treatment discussions among HNC patients and their doctors. We found that in only $6 \%$ of the consultations doctors provided quantitative prognostic information, by discussing numbers, such as percentages. In $94 \%$ qualitative prognostic information was provided, by using words such as "curable" and "good prospect" [11]. The current study is the second step in our qualitative research by exploring HNC patients' preferences and views on receiving prognostic information. Relatively little attention has been paid to this topic. Some cancer patients want to know everything, while others are overwhelmed by too much information. Furthermore, each patient group has its own characteristics and preferences. For example, patients with breast cancer are considered to have high information needs [12]. To our knowledge, there are no studies published that explore HNC patients' views on receiving quantitative prognostic information. Therefore, research is needed on what these patients want to know about their prognosis and in which manner they wish this information to be conveyed to enable better counseling and patient-centered care.

Physicians are often unable to forecast an individual's life-expectancy and tend to overestimate survival [13] (Hoesseini A, Offerman MPJ, van de Wall - Neecke BJ, Sewnaik A, Wieringa MH, Baatenburg de Jong RJ: Physicians' clinical prediction of survival in head and neck cancer patients in the palliative phase, submitted). This can lead to concerns of being proved inaccurate and therefore reluctance to discuss the prognosis [14]. Survival rates of cancer are traditionally based on the TNM-classification of the tumor. These are however general estimates of a heterogeneous group of patients and not tailored to an individual's prospect. Prognostic models that include patient specific predictors, like age and co-morbidity, could help doctors to provide a more personalized prognosis. Over the last years, an internally and externally validated prognostic model named "OncologIQ" has been developed. This model estimates the 1- to 10-year overall survival (OS) of patients with primary $\mathrm{HNC}$, based on the average treatment effect [15-17]. Besides tumor location and TNM-classification, OncologIQ includes age, sex, and the Adult Comorbidity

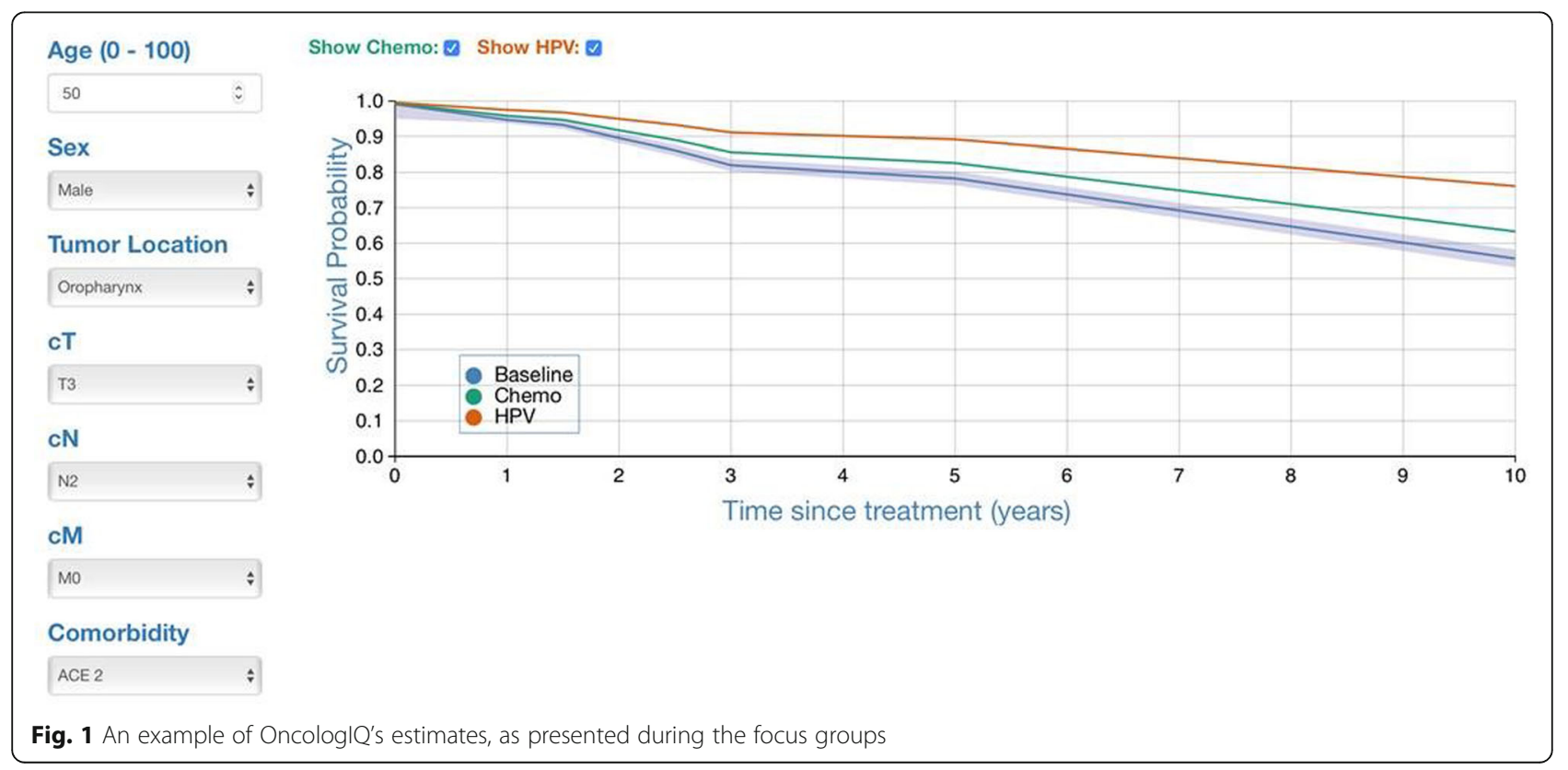


Evaluation 27 (ACE-27) as prognostic factors for OS (see also Fig. 1) [15-17]. The benefit of having a HPV-positive tumor or receiving chemotherapy were added by an adaptation method. This model could support doctors with prognostication during patient encounters, by providing more personalized estimates of the OS. However, it remains unclear if, how, and when this prognostic information should be shared with HNC patients? Furthermore, how should one visualize the individual survival estimates and in which manner should healthcare providers explain the results? While more prognostic models are developed, there is a dearth of evidence on the impact of the use of such models in clinical practice [18], and to what level patients appreciate and understand the information provided [19]. Our study fills this gap by exploring patients thoughts on OncologIQ.

The aim of the current study was to explore 1) HNC patients' preferences for receiving prognostic information, 2) and their views on the prognostic model Onco$\operatorname{logIQ}$. By assessing patients' views on these topics, we can optimize counseling between physicians and patients. In addition, a clinical practice guideline on how to use OncologIQ for individualized prognostic counseling was developed.

\section{Methods}

We conducted a single center qualitative study by organizing five focus groups with $\mathrm{HNC}$ patients and their caregivers between December 2016 and February 2017. Methods and results are described using the Consolidated Criteria for Reporting Qualitative Research (COREQ) [20].

\section{Definition of prognosis}

In this study we refer to the concept of prognosis from two different angles:

1) Qualitative information: general terms like "the cancer is curable".

2) Quantitative information: numbers or percentages, like survival rates.

\section{Research team \& reflexivity}

The research team consisted of three investigators. M.P.J. Offerman (MO), $\mathrm{PhD}$, is a psychologist and has several years of experience with focus group research. The second investigator, A. Hoesseini (AH), MD, is a physician, clinical epidemiologist, and PhD candidate. The third investigator, E.A.C. Dronkers (ED), MD, is also a physician, clinical epidemiologist, and $\mathrm{PhD}$ candidate. $\mathrm{MO}$ and $\mathrm{AH}$ conducted the focus groups. There was no relationship established with the participants prior to the beginning of the study. Treating physicians were not allowed to attend the focus groups, so participants would not feel reluctant to share their thoughts.

\section{Study design}

This study was approved by the ethics committee of the Erasmus Medical Center (MEC-2013-052). After consulting experienced head and oncologists on how the groups should be selected, we divided patients in five common treatment groups, which is a reflection of the patient population we treat in our hospital: 1) small laryngeal carcinomas treated with radiotherapy or laser, 2) extensive oral cavity procedures, 3) total laryngectomy, 4) chemoradiation, 5) other treatments (local

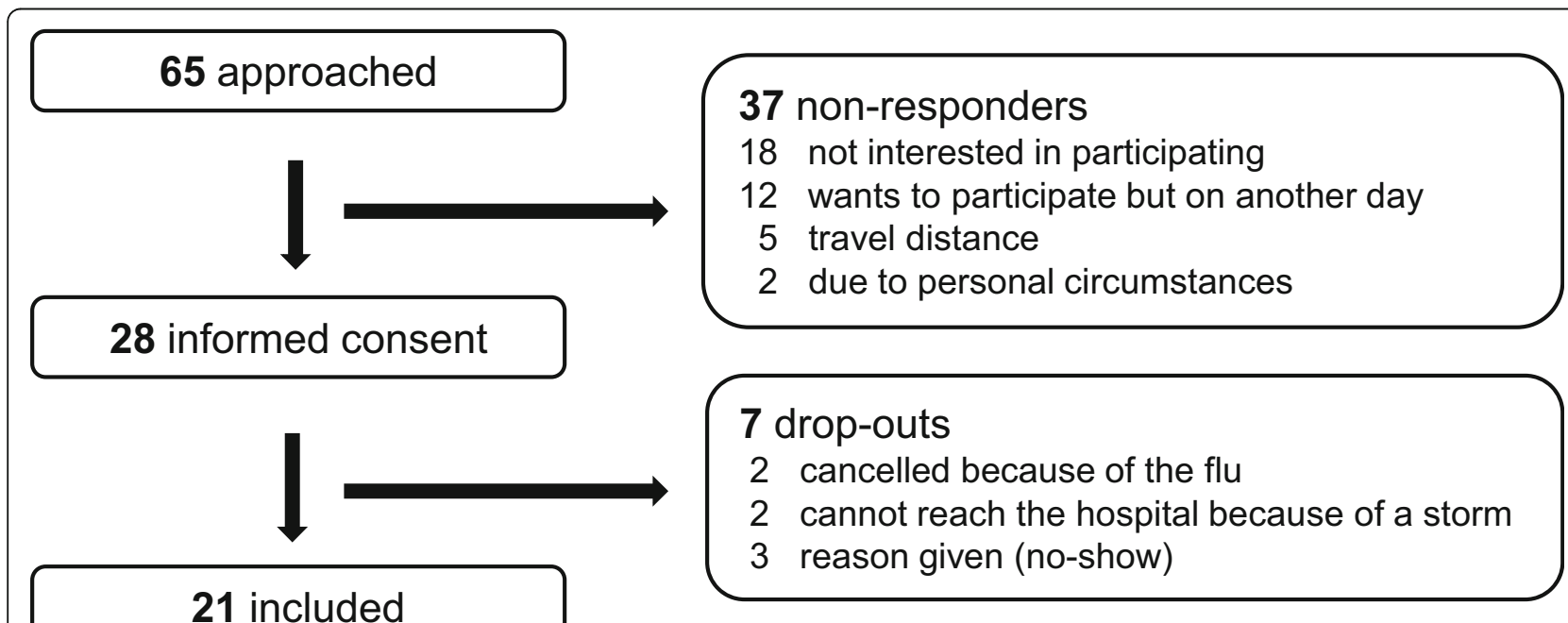

Fig. 2 Patient selection procedure. Exclusion criteria were: aged 80 years or older; a carcinoma in situ; Korsakoff syndrome or dementia; severe alcohol and/or drugs abuse; possible recurrent or metastatic disease; recent hospitalization; simultaneous tumor outside of the head and neck region 
resection, neck dissection etc.). In this way, we selected patients who had a shared experience and thus were more likely to feel understood by each other. Based on the theory of social comparison [21], patients with a similar background feel more recognized and consequently less reluctant to share their thoughts.

Participants were consecutively selected by $\mathrm{AH}$ if they had undergone treatment for $\mathrm{HNC}$ in the Erasmus MC Cancer Institute, 6 to 18 months before selection. Patients were approached by telephone and information about the content and the working procedure of the focus groups was given. They were told that we wanted to learn from their experiences, with a main focus on how they had experienced the counseling by the healthcare providers. In order to limit selection bias, specific information on OncologIQ was not given in advance. Caregivers were encouraged to accompany patients. See Fig. 2 for the patient selection and exclusion criteria. Also, information on nonparticipants in shown in Fig. 2. In total 21 patients gave their informed consent and participated. All focus groups were held in the same conference room in the Erasmus $\mathrm{MC}$ Cancer Institute. Two volunteers were present during each focus group to welcome the patients. The volunteers did not know the patients and did not actively participate in the focus groups. Data were stored anonymously by study ID and were only accessible by the research team.

\section{Interview guide}

An interview guide was made prior to the start of the focus groups (see Additional files 1 and 2). The main topics were 1) life-expectancy, and 2) the prognostic model OncologIQ. Each topic was first briefly introduced by $\mathrm{AH}$ and $\mathrm{MO}$ using a PowerPoint presentation (see Additional files 1 and 2). Subsequently closedended questions, using small cards, were answered by patients themselves. This enabled patients to react individually without being affected by the opinion of the other participants and their caregivers. The closedended questions were followed by open-ended questions to stimulate the group discussion, and caregivers were also encouraged to participate to a certain extent, as patients' perspective was the main focus. Caregivers were invited as they are the main source of support for the patient and are often present during treatment decision consultations. Similar to these conversations, in the end the patient decides what kind of prognostic information is shared. OncologIQ was introduced only after the topic "life-expectancy" was thoroughly discussed. This order was deliberately chosen as we wanted to explore life-expectancy unbiased before introducing the prognostic tool. The model was demonstrated by showing a hypothetical patient with a different kind of tumor than the patients present in the focus group. The interview guide and presentation were adjusted once after the first focus group. In this first focus group we introduced quantitative terms like "5-year survival" directly after discussing lifeexpectancy in qualitative terms such as "curable". This resulted in confusion among patients and caregivers. They interpreted the 5-year survival rate as "being told you only have five more years left to live" or confused it with the 5-year follow-up after the diagnosis. Therefore, we decided to introduce life-expectancy in qualitative terms more extensively before the break and introduce quantitative terms like 5-years survival after the break in the next focus groups. We also added one quantitative question on whether the physician should use a chart when explaining survival rates. After these adjustments no problems were encountered in focus group two until five, and therefore no further adjustments were made. All focus groups were digitally recorded. The mean duration of the focus groups was $2 \mathrm{~h}$ and $7 \mathrm{~min}$. The focus groups were transcribed by $\mathrm{AH}$ and one of our volunteers.

\section{Data analysis}

The grounded theory approach was used to analyze the data. This implies that the researcher moves back and forth between the population under study and analysis of the data, so that an explanatory theory evolves through an iterative process [22]. Two researchers ( $\mathrm{AH}$ and $\mathrm{MO})$ coded all transcripts and discussed the coding for each group until consensus was reached. Themes were derived from the coded data by $\mathrm{AH}$ and $\mathrm{MO}$ individually. These themes were discussed and if necessary rearranged, starting with one focus group, and adding the others one by one. When there was no agreement on the themes or on the matching of quotations with the themes, consensus was reached after an in-depth discussion. After discussing the fourth focus group, no new themes were identified and therefore data saturation occurred. The next step was verification of the results by the third researcher (ED). She was given parts of coded transcripts and was asked to match them with the identified themes, and if deemed necessary suggest new themes or codes. No new themes were identified by ED, however some (sub) themes were rearranged. Finally, one quotation per (sub) theme was jointly chosen to include in the results section. NVivo 12 was used to manage the data. The participants did not provide feedback on the findings.

\section{Results}

\section{Participants}

Table 1 shows an overview of the number of patients and caregivers in each focus group, and patient characteristics. In total 17 patients (81\%) were accompanied by their caregiver(s). In $15 / 17$ of the cases $(88 \%)$ this was a partner. One patient took a sibling with her and one 
Table 1 (a) Number of participants and (b) patient characteristics

\begin{tabular}{|c|c|c|}
\hline FOCUS GROUPS & PATIENTS & CAREGIVERS \\
\hline 1. small laryngeal carcinomas treated with radiotherapy / laser & $6(28.6 \%)$ & $6(31.6 \%)$ \\
\hline 2. extensive oral cavity surgical procedures & $2(9.5 \%)$ & $2(10.5 \%)$ \\
\hline 3. total laryngectomy & $4(19.0 \%)$ & $6(31.6 \%)$ \\
\hline 4. chemoradiation & $523.8 \%)$ & $3(15.8 \%)$ \\
\hline 5. other treatments ${ }^{a}$ & $4(19.0 \%)$ & $2(10.5 \%)$ \\
\hline Total no. of participants per focus group $(\%)^{b}$ & $21(100 \%)$ & $19(100 \%)$ \\
\hline PATIENT CHARACTERISTICS & NO. (\%) / MEDIAN (Q1-Q3) & \\
\hline Age, years & $65.0(53.5-68.5)$ & \\
\hline Age range, years & $33-78$ & \\
\hline \multicolumn{3}{|l|}{ Sex } \\
\hline male & $12(57.1 \%)$ & \\
\hline female & $9(42.9 \%)$ & \\
\hline \multicolumn{3}{|l|}{ Tumor localization } \\
\hline larynx & $9(42.9 \%)$ & \\
\hline hypopharynx & $2(9.5 \%)$ & \\
\hline oral cavity & $3(14.3 \%)$ & \\
\hline oropharynx & $6(28.6 \%)$ & \\
\hline unknown primary & $1(4.8 \%)$ & \\
\hline \multicolumn{3}{|l|}{ Tumor stage } \\
\hline । & $5(23.8 \%)$ & \\
\hline$\|$ & $3(14.3 \%)$ & \\
\hline III & $5(23.8 \%)$ & \\
\hline IVa & $7(33.3 \%)$ & \\
\hline $\mathrm{IVb}$ & $1(4.8 \%)$ & \\
\hline \multicolumn{3}{|l|}{ Marital status } \\
\hline married / durable relationship & 19 (90.5\%) & \\
\hline single & $2(9.5 \%)$ & \\
\hline \multicolumn{3}{|l|}{ Education level } \\
\hline lower (primary education or less / lower secondary) & $7(33.3 \%)$ & \\
\hline intermediate (upper secondary / post-secondary non-tertiary) & $9(42.9 \%)$ & \\
\hline tertiary (short cycle tertiary / bachelor / master / doctoral) & $4(19.0 \%)$ & \\
\hline missing & 1 & \\
\hline Median time between end of treatment and participation in the focus group (Q1 - Q3) & 47 weeks $(35-64)$ & \\
\hline
\end{tabular}

${ }^{a}$ For example neck dissection or local resection

${ }^{b}$ Two patients were treated for cancer recurrence by a total laryngectomy, the remaining were treated for a primary head and neck tumor

patient was accompanied by both his partner and two children. Education level was categorized according to the International Standard Classification of Education [23, 24]. Patients' age and sex were similar to national HNC data gathered in the Netherlands Cancer Registry (NCR) by the Netherlands Comprehensive Cancer Organization (IKNL) [25]. Patients education level was more or less similar to a recent study among 2189 consecutive HNC patients in our tertiary center (Hoesseini A, van Leeuwen N, Offerman MPJ, Zhang J, Dronkers EAC, Sewnaik A, Lingsma, HF, Baatenburg de Jong, RJ:
Predicting survival in head and neck cancer: external validation and update of the prognostic model OncologIQ in 2189 patients, submitted). This did not apply to marital status: while in the latter study $28 \%$ of patients were single, in the focus groups only $10 \%$ were.

\section{Life-expectancy}

After the introduction of the main topic life-expectancy, we first asked patients the closed-ended question: To what extent do you think it is important to receive information about your life expectancy? (4-point Likert-scale, 


\section{1) LIFE-EXPECTANCY}
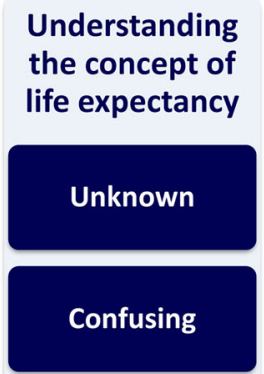

Wrong / negative formulation

\section{Tailor-made approach}

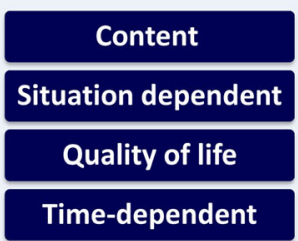

Personal preferences Initiator
2) OncologiQ

\section{Communication skills professional}

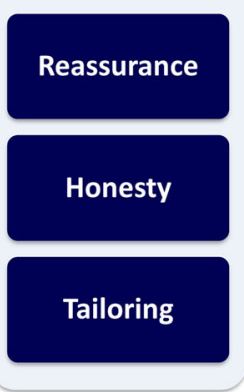

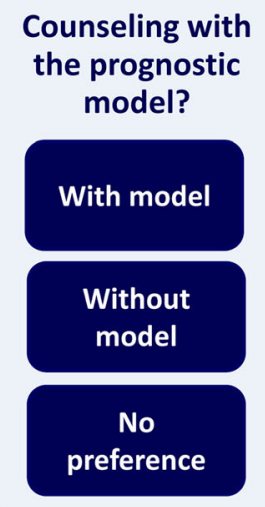

Fig. 3 Code trees of themes and subthemes derived from the topics 1) life-expectancy and 2) the prognostic model OncologlQ

"not at all important" to "very important", see also attachment 1). $62 \%$ of patients answered "very important", the remaining eight (38\%) answered "somewhat important". Hereafter, open-ended questions were asked (see interview guide) to stimulate the group discussion. From the transcripts of these discussions in total three themes and 12 subthemes were derived (see Fig. 3 for the code tree and Table 2 for the contents).

\section{The prognostic model OncologlQ}

Table 3 gives an overview of the themes that were derived from the discussions on OncologIQ (see also Fig. 3 for the code tree). In addition, several recommendations were shared. Table 4 shows several visual formats of communication and patients' preferences for the selected charts. The pie chart was the most preferred chart. All patients in focus group two until five $(n=15)$ preferred the combination of verbal explanation of survival rates and a visual presentation with a chart, over a verbal explanation solely. This was deemed easier to understand.

\section{Discussion}

\section{Life-expectancy}

Understanding the concept \& using a tailor-made approach To our knowledge, this is the first study offering in-depth understanding of HNC patients' preferences for disclosure of prognostic information, and the use of a prognostic model during treatment decision consultations.

While all patients considered it somewhat to very important to receive information about their lifeexpectancy, only some of them wanted to receive this in a specific quantitative manner, like 5-year survival rates. This is in line with previous research among patients with advanced or incurable cancer [26, 27]. The majority of patients wanted to receive prognostic information from their doctor in general terms, like 'your cancer can be well treated'. This kind of qualitative information would give these patients enough reassurance for the first moment. Even though doctors generally use the concept 5-year survival rate, participants often did not understand this concept or confused it with other terms, for example chances of cure, and thought it had a negative connotation. Overall, little is known about patients' awareness, and understanding of prognosis [6]. Previous research stressed that in some cases cancer patients misunderstand or fail to absorb the information given, cannot recall the status of their disease and often overestimate their survival chances $[6,28-30]$. The need for receiving prognostic information was dependent on different circumstances. This means that sharing prognostic information requires a tailor-made approach. Patients had a stronger preference for quantitative information like months or survival rates, in the hypothetical case of cancer recurrence and/or a poor prognosis. This kind of information would enable them to weigh whether undergoing a second treatment to prolong survival would be worth the 'costs'. Prognostic information is not a standalone concept according to patients and caregivers. Patients also expressed the need for information about their expected QoL, since this would be of significant importance in the decisionmaking process. Fried et al. asked 226 patients with a limited life expectancy whether they would choose a treatment with survival, but with severe functional or cognitive impairment. $74.4 \%$ of patients answered they would not accept severe functional impairment and $88.8 \%$ would not accept cognitive impairment, and thus rather face death [31]. However, more recent research by Blanchard et al. among HNC patients showed that they overall prioritize survival over functional endpoints [32]. Although we did 


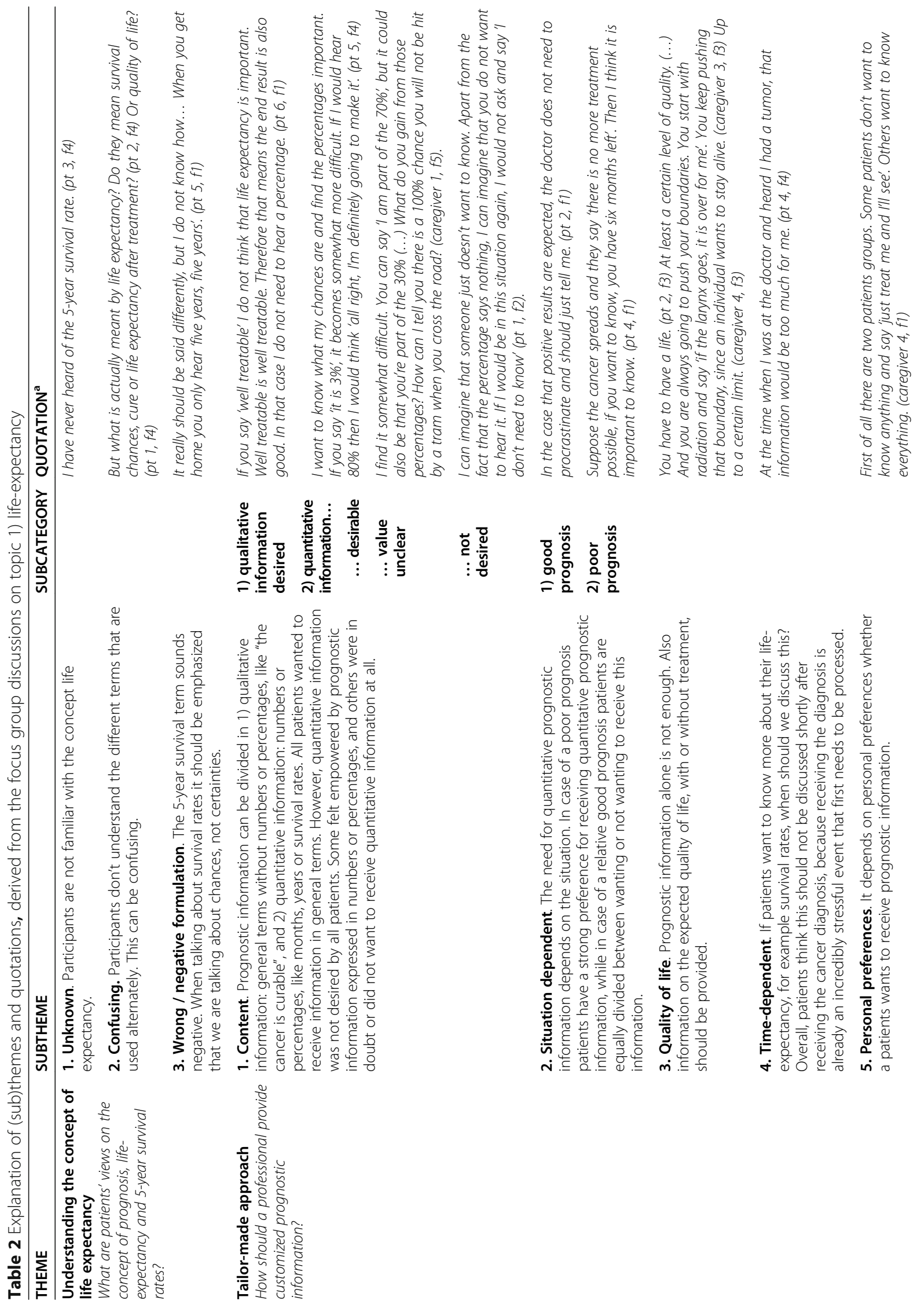




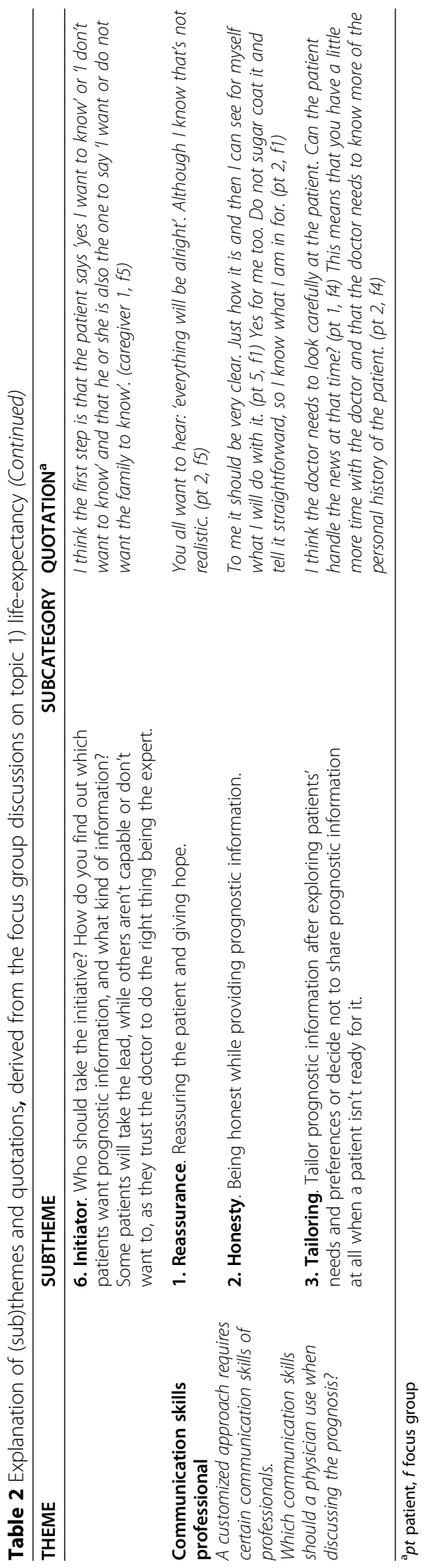


Table 3 (a) Explanation of (sub)themes, (b) recommendations and quotations, derived from the focus group discussions on topic 2) prognostic model OncologlQ

\begin{tabular}{|c|c|}
\hline THEME & SUBTHEME \\
\hline \multirow[t]{3}{*}{$\begin{array}{l}\text { Counseling with the } \\
\text { prognostic model? } \\
\text { How do patients feel and } \\
\text { think about counseling } \\
\text { with OncologlQ? }\end{array}$} & $\begin{array}{l}\text { With model. Some patients want to be counselled with the } \\
\text { prognostic model. They think it gives a clear overview of } \\
\text { their survival chances, and provides a personal estimate of } \\
\text { their survival rates. }\end{array}$ \\
\hline & $\begin{array}{l}\text { Without model. Some patients don't want to be } \\
\text { counselled with the model. They find it too confronting, or } \\
\text { just don't feel the need to receive counselling with a } \\
\text { prognostic model. Others think the model doesn't include } \\
\text { enough prognostic factors yet. }\end{array}$ \\
\hline & $\begin{array}{l}\text { No preference. Some patients don't have a specific } \\
\text { preference, as they see both advantages and disadvantages } \\
\text { of receiving prognostics information with a model. }\end{array}$ \\
\hline
\end{tabular}

\section{RECOMMENDATIONS}

Add additional prognostic factors, in order to make the prediction more individualized.

\section{Add treatment modalities if possible.}

Include quality of life as an outcome in the model.

Provide structural information to make sure every patient is informed about the possibility to discuss the individual prognosis with OncologlQ.

This prognostic information should be given by someone else than the physician, as the participants thought this task would be too time-consuming and stressful for the physician. They opted to trust this task to a specialized nurse. In addition, one caregiver suggested to integrate this in our Healthcare Monitor.

Take concerns about the health insurance into account. In three focus groups caregivers shared their concerns about hypothetical consequences for the health insurance.

Show and explain all variables that are included in OncologlQ. This enables patients to understand which variables are used to calculate their prediction.

Use the 5-year survival rate. When discussing survival rates, participants prefer using the 5-year survival rates instead of 1- or 10-year survival rates, unless the individual patient prefers otherwise.

Create the possibility to view OncologlQ in a patient portal.

QUOTATIONS

It makes it more personal I think. It applies more to you personally. (caregiver 2, f3)

If I'm part of the big group, I have more alternative possibilities. (pt 1, f5)

I sit on the fence a little. I think it is more confronting, but also somewhat more realistic. It is close to home and that can be frightening. So I am not sure whether I want it like that. (pt 4, f5)

\section{QUOTATIONS}

I actually think it's pretty unreliable. You should fill in many more things, like does the patient smoke, drink, and exercise? (pt 2, f4)

Can you add radiotherapy in this model? (caregiver 1, f2)

This model says nothing about the quality of life. (caregiver 3, f3)

People should be able to indicate in advance whether they want to know this or not. (pt 4, f5)

I think it's too much for a doctor. You become a doctor to help patients, but to really get to know the human psyche is something else. (caregiver 2, f5)

Then the premium will increase. (caregiver 2, f3)

I think you should show the variables. This enables you to see what the prediction is based on. (pt 3, f3)

pt patient, $f$ focus group

not explicitly ask patients to prioritize survival and QoL, they did however mention that at a certain point the survival benefits would not weigh against the deterioration in QoL. On the other hand they mentioned that patients are prone to keep pushing their boundaries, and increasingly accept functional limitations in order to stay alive.

In case patients want to receive quantitative information, what would be the right timing to share this? Our focus group results suggest that the right timing and phasing are of key importance. It seems that lifeexpectancy should be best discussed after the conversation in which the cancer diagnosis is given. According to most patients and their caregivers, it would be too stressful to discuss this all at once.

Several patients addressed that it depends on personal preferences whether a patient wants to receive prognostic information. While on the one hand some patients gain an increased sense of control by receiving more information about their disease and prognosis, others want to receive very little information. The latter group often wants the doctor to take control and is not interested in the details on treatment or prognosis. Receiving unwanted prognostic information could destroy hope and therefore patients' needs should be explored beforehand [33], instead of bluntly confronting them with unwanted information. Who should take the initiative in exploring prognostic information needs? While some patients will take the lead, others aren't capable or don't want to. Therefore, according to the participants, the healthcare provider should be the one to introduce the topic, while the patient is given the opportunity to decide whether he or she wants to receive the information. This is in agreement with a qualitative research among advanced cancer patients: most patients and 
Table 4 Visual formats of communication: chart preferences and patient quotations. Patients were asked which figure they would prefer when talking about life-expectancy*

$1^{\text {st }}$ pie chart (91 points)

$2^{\text {nd }}$ bar chart (62 points)

$3^{\text {rd }} 100$-person diagram (58 points)
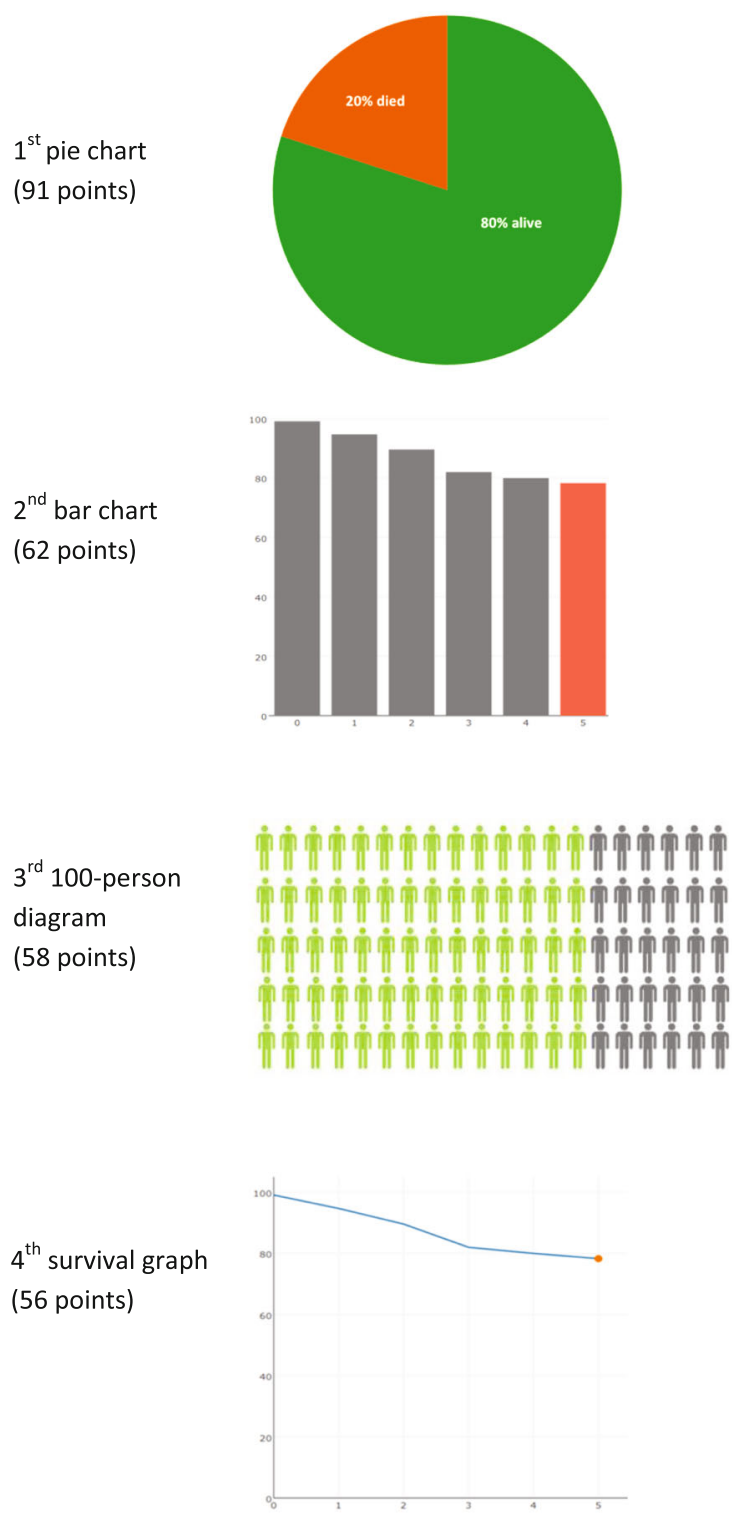

$5^{\text {th }} 100$ - square chart (48 points)

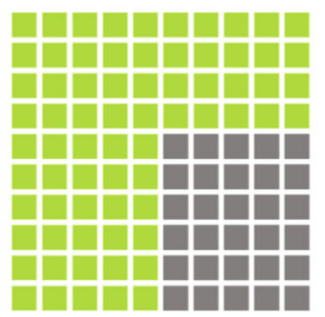

pro: Black and white situation where you see at a glance "oh that's it". You do not have to think about it. (pt 2, f1)

con: I only see "died". Deceased and gone. (pt 1, f5)

pro: -

con: I don't like it. (pt 4, f1)

pro: It is clear at a glance. (pt 2, f4)

con: Too confronting. (pt 4, f5)

These are just like people. (pt $3, f 5)$

pro: The graph is less harsh. I think it's the nicest and most positive one. (caregiver $2, f 5$ )

con: You always have a $X$-axis and $Y$-axis that you first need to interpret. (pt 6, f1) I find it too mathematical. (pt 2, f4)

pro: -

con: I don't like it at all (several patients).

*First choice nomination resulted in five points, last choice nomination in one point. In total 315 points were divided. Figure 2 until 5 also included captions with the ' $\%$ died' versus ' $\%$ survive', and if applicable captions of the $x$ - and $y$-axis (not shown in this table) 


\section{STEP 1}

Uncover latent needs for individual prognostic information in an early phase by providing structural information for all new patients during the intake. This can be both verbal and written information.

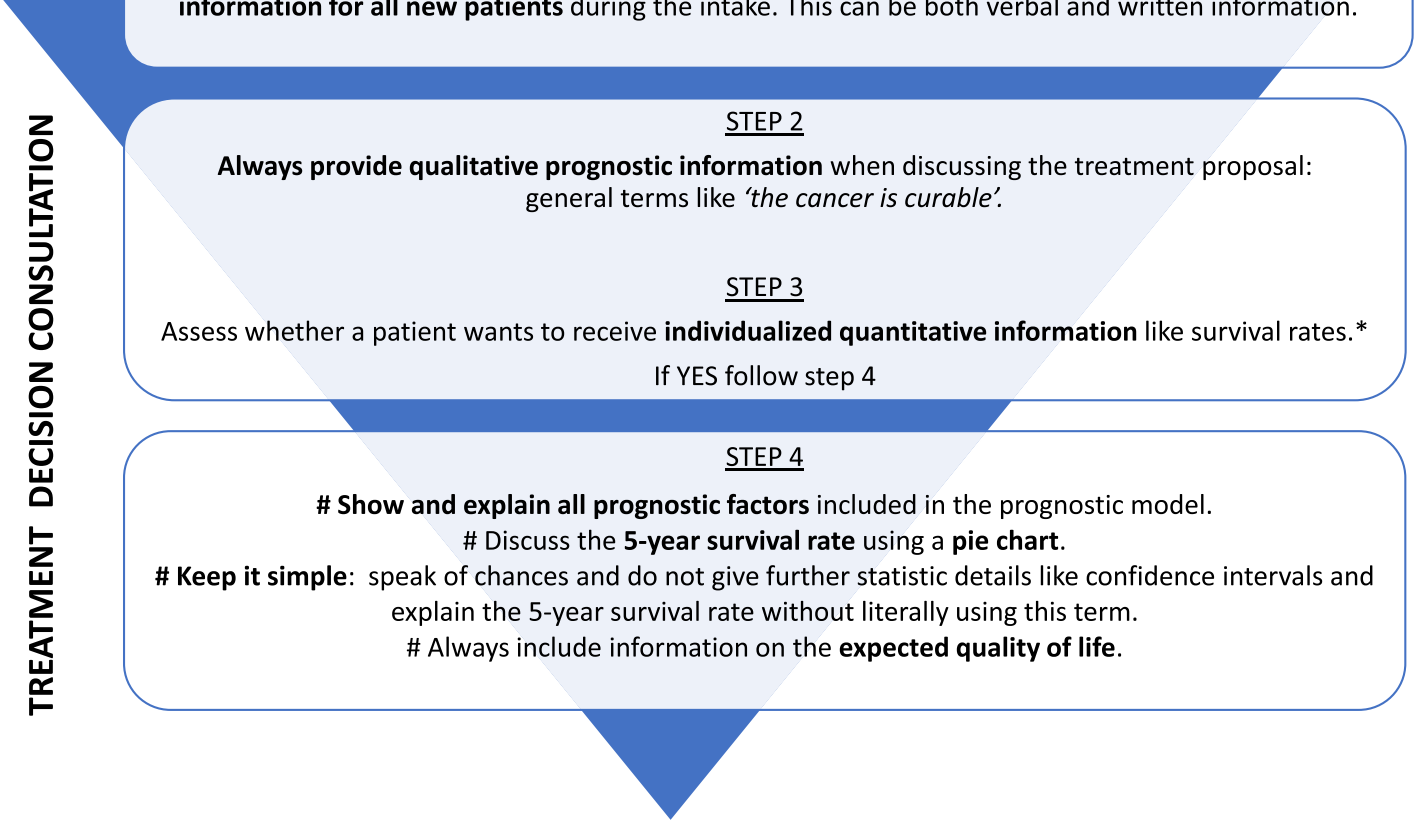

Fig. 4 Clinical practice guideline for individualized prognostic counseling. *Keep the following in mind: do not to discuss life-expectancy in the same consult in which the cancer diagnosis is discussed but hereafter

caregivers in this study said a physician should offer to discuss the prognosis, if the option to decline the information was also provided [34].

\section{Communication skills professional}

According to our participants, doctors should be honest while discussing the prognosis without taking away hope, and tailor prognostic information after exploring patients' needs. The importance of being realistic and honest while maintaining hope is also identified in previous literature on patients with advanced or incurable cancer [35-38]. For example, Kutner et al. found that while $100 \%$ of patients in their survey wanted honesty from clinicians, 91\% also wanted them to be optimistic [35]. Balancing between honesty while disclosing prognosis and maintaining hope can be a challenging task for healthcare providers [37, 39].

\section{The prognostic model OncologIQ}

After fully exploring patients thoughts and believes on the topic life-expectancy, the prognostic model OncologIQ was introduced. Some patients would appreciate counseling with OncologIQ as they thought it was clear and more personalized, while others were in doubt. Some patients didn't want counseling with OncologIQ at all because of the need to maintain some ambiguity about the future. This need to maintain ambiguity about outcomes, is also identified in previous research among advanced or incurable cancer patients [27, 33, 36]. Ambiguity could help to maintain hope and avoids a blunt confrontation with the facts. Participants shared several recommendations to improve the model. In three focus groups caregivers were concerned that the monthly health insurance premium would rise, if the insurance companies would also have access to an individuals' prognostic estimate. Questions on this topic should be considered when using a prognostic model for counseling.

\section{Visual formats of communication}

Prognosis can be presented in various formats. While previous research showed that most persons find numbers and 100-person diagrams easiest to understand [40, 41], the HNC patients in this study preferred the pie chart. The pie chart was a favorite because they thought it was clear at a glance (see Table 4) and less confronting than some of the other formats. The 100-person diagram was considered too confronting by both patients and caregivers. This is in line with previous research that explored this by using a 100-faces diagram [41]. In addition, Davey et al. stated that the survival graph was considered negative, since it showed the constantly increasing 
mortality. In the current study, patients' thoughts on the survival graph were also mostly negative. They found it too mathematical, since one must first must interpret the $\mathrm{X}$ - and Y-axis. Davey et al. also tested cancer patients' understanding of the survival graph: only six out of 26 patients correctly interpreted the graph [41]. Furthermore, we assessed that the included patients' preferred to combine verbal explanation with visual prognostic information over a verbal explanation solely. This is also reported in previous research on this topic [42]. Furthermore, it remains unclear as to what extent patients understand the uncertainty around prognostic models' estimates [43]. Presenting data uncertainty is difficult and there is no consensus in literature about the optimal way to communicate different types of uncertainty $[43,44]$.

\section{Practice implications: a guideline for individualized prognostic counseling}

OncologIQ could take away physicians reluctance to discuss the prognosis and reduce ambiguity in case of conflicting opinions among healthcare professionals by providing individual estimates. Previous research showed physicians' willingness to use prognostic models in end-of-life care, aiming to improve prognostic confidence [14]. It also enabled physicians' to take a more directive role in specific cases where the expected prognosis significantly differs from patients' expectations, and it reduced ambiguity in case of conflicting opinions about prognosis among colleagues [14]. Based on the results of this focus groups study, especially the recommendations discussed in Table 3, a clinical practice guideline was developed that includes basic steps for sharing individualized prognostic information (see Fig. 4). While our earlier published guideline for professional communication focuses on general aspects of sharing prognostic information with HNC patients [11], this guideline specifically focuses on how to share the information provided by the prognostic model OncologIQ. It could also be used for other similar prognostic models in HNC. Since the term "5-year survival rate" seemed to confuse patients and caregivers, we recommend not to use it literally. We asked patients which survival period would be most appropriate if a patient wants quantitative prognostic information. Most patients preferred five years, as they deemed two years "too short" and 10 years "too far ahead".

\section{Strengths and limitations}

One must first listen to patients' preferences and needs, to be able to provide patient-centered care. The use of a qualitative methodology provided us with rich data on HNC patients' preferences on these vital but unexplored topics. However, it is difficult to make assumptions on its generalizability. This study focused on patients with HNC in the curative setting. Since each setting has its own concerns, the generalizability of these results to the incurable setting is not desirable. Also, our results may be different in other, non-Western, cultures or countries. A certain selection bias may have occurred as the included patients are willing to participate in a focus group with other patients and caregivers. In addition, while almost one third of the patient population in our center is single, only $10 \%$ of patients in the focus group were. The presence of family members or other caregivers adds complexity to prognostic discussions since they may have different information needs [45]. However, we purposely chose to include caregivers in the focus groups, as they are also present during the treatment decision consultation.

\section{Future perspectives}

The results of the current study have been used to improve OncologIQ. Recently, the prognostic model has been updated (Hoesseini A, van Leeuwen N, Offerman MPJ, Zhang J, Dronkers EAC, Sewnaik A, Lingsma, HF, Baatenburg de Jong, RJ: Predicting survival in head and neck cancer: external validation and update of the prognostic model OncologIQ in 2189 patients, submitted). In the first place because the original model was based on outdated data as the survival of HNC patients has improved in the past years [46]. The second aim of the update was to test whether adding new prognostic factors would improve model performance, as recommended during the focus groups. Also, a visual format for patients has been developed, including a pie chart of the 5year survival rate. The updated model can be found on www.oncologiq.nl. The next step will be to evaluate the clinical impact of OncologIQ in a prospective clinical trial. The primary outcome of this trial is decisional conflict among HNC patients who are counselled with and without the model during treatment decision consultations. The effect of the use of OncologIQ in our multidisciplinary tumor board meetings is also recently assessed in a pilot study.

A future aim would be to develop a prognostic model that includes both survival and QoL for HNC patients. Despite not addressing this future prospective during the focus groups, several patients stressed the importance of combining both survival and QoL, rather than focusing solely on survival. Due to the implementation of our Healthcare Monitor we will be able to meet this need soon (Dronkers EA, Baatenburg de Jong RJ, van der Poel EF, Sewnaik A, Offerman MP: Implementation of a standardized value based clinical support system 'Healthcare Monitor' for routine symptom monitoring of head and neck oncology patients, submitted). With this monitor we are collecting electronically patient reported outcomes (ePRO) on physical and psychosocial functioning since 2013, from intake until the last follow-up visit. In the first place this is 
done to improve patient care and counseling, although these data could also be used for research purposes.

\section{Conclusions}

This study is first in examining HNC patients' preferences for disclosure of prognostic information, and the use of a prognostic model. Overall, the findings of the current study highlight the importance of exploring patients' thoughts and needs, in order to enhance patient-centered care. The participants found it important to receive information on their life-expectancy. While disclosing prognostic information in general terms like "the cancer is curable" gave enough reassurance for most patients, some also wanted numerical information like OncologIQ's prognostic estimates. A tailor-made approach is necessary to provide this prognostic information in a customized manner. A clinical practice guideline was developed to support the healthcare professional in sharing individualized prognostic information, aiming to improve shared decision making.

\section{Supplementary information}

Supplementary information accompanies this paper at https://doi.org/10. 1186/s12885-020-6554-8.

Additional file 1: Material S1. Interview guide: overview of the topics and corresponding questions.

Additional file2: Material S2. PowerPoint presentation that was used during the focus groups.

\section{Abbreviations}

COREQ: Consolidated Criteria for Reporting Qualitative Research; ePRO: Electronically Patient Reported Outcomes; HNC: Head and Neck cancer; QoL: Quality of Life; SDM: Shared Decision Making

\section{Acknowledgements}

We would like to thank all the patients and caregivers that gave their time and energy to this study. We would also like to thank the volunteers for their help, and, in particular Hester van Willigen, who helped us to transcribe the recordings.

\section{Authors' contributions}

$\mathrm{AH}$ and $\mathrm{MO}$ served as co-principle investigators and conceived the study. $\mathrm{AH}$ recruited study participants and transcribed the data. $\mathrm{AH}$ and $\mathrm{MO}$ conducted the focus groups and analyzed and interpreted the data. AH took primary responsibility for writing the manuscript. ED contributed to data analysis, data interpretation and manuscript revision. AS, JH, RBJ contributed to the study design and critically revised the manuscript. All authors commented on the drafts and approved the final draft. $\mathrm{AH}$ is the corresponding author (a.hoesseini@erasmusmc.nl).

\section{Funding}

This research did not receive any specific grant from funding agencies in the public, commercial, or not-for-profit sectors.

\section{Availability of data and materials}

The datasets generated and/or analyzed during the current study are not publicly available due to the qualitative content of the dataset. The ful dataset could contain information that might compromise research participants' privacy and/or their conditions of consent. The data that support the findings of this study may be available on reasonable request from the corresponding author $[\mathrm{AH}]$.

\section{Ethics approval and consent to participate}

This study was approved by the ethics committee of the Erasmus Medical Center (MEC-2013-052). Although no identifying information is used, the study participants provided informed consent in the form of verbal agreement at the beginning of each focus group interview. In addition, all patients signed an informed consent form.

\section{Consent for publication}

Not applicable.

\section{Competing interests}

The authors declare that they have no competing interests.

Received: 22 July 2019 Accepted: 17 January 2020

Published online: 07 May 2020

\section{References}

1. Vokes EE, Weichselbaum RR, Lippman SM, Hong WK. Head and neck cancer. N Engl J Med. 1993;328(3):184-94.

2. De Boer MF, McCormick LK, Pruyn JF, Ryckman RM, van den Borne BW. Physical and psychosocial correlates of head and neck cancer: a review of the literature. Otolaryngol Head Neck Surg. 1999:120(3):427-36.

3. Ferlay J, Soerjomataram I, Dikshit R, Eser S, Mathers C, Rebelo M, et al. Cancer incidence and mortality worldwide: sources, methods and major patterns in GLOBOCAN 2012. Int J Cancer. 2015;136(5):E359-86.

4. Gupta B, Johnson NW, Kumar N. Global epidemiology of head and neck cancers: a continuing challenge. Oncology. 2016;91(1):13-23.

5. Hung TM, Lin CR, Chi YC, Lin CY, Chen EY, Kang CJ, et al. Body image in head and neck cancer patients treated with radiotherapy: the impact of surgical procedures. Health Qual Life Outcomes. 2017;15(1):165.

6. Hagerty RG, Butow PN, Ellis PM, Dimitry S, Tattersall MH. Communicating prognosis in cancer care: a systematic review of the literature. Ann Oncol. 2005:16(7):1005-53.

7. Ghandourh WA. Palliative care in cancer: managing patients' expectations J Med Radiat Sci. 2016:63(4):242-57.

8. Step MM, Ferber GA, Downs-Holmes C, Silverman P. Feasibility of a team based prognosis and treatment goal discussion (T-PAT) with women diagnosed with advanced breast cancer. Patient Educ Couns. 2019;102(1):77-84

9. Charles C, Gafni A, Whelan T. Shared decision-making in the medical encounter: what does it mean? (or it takes at least two to tango). Soc Sci Med. 1997:44(5):681-92.

10. Stiggelbout AM, Van der Weijden T, De Wit MP, Frosch D, Legare F, Montori VM, et al. Shared decision making: really putting patients at the Centre of healthcare. BMJ. 2012;344:e256.

11. Dronkers EAC, Hoesseini A, de Boer MF, Offerman MPJ. Communication of prognosis in head and neck cancer patients; a descriptive qualitative analysis. Oral Oncol. 2018:84:76-81.

12. Halkett GK, Kristjanson LJ, Lobb E, Little J, Shaw T, Taylor M, et al. Information needs and preferences of women as they proceed through radiotherapy for breast cancer. Patient Educ Couns. 2012;86(3):396-404.

13. White N, Reid F, Harris A, Harries P, Stone P. A systematic review of predictions of survival in palliative care: how accurate are clinicians and who are the experts? PLoS One. 2016;11(8):e0161407.

14. Hallen SA, Hootsmans NA, Blaisdell L, Gutheil CM, Han PK. Physicians' perceptions of the value of prognostic models: the benefits and risks of prognostic confidence. Health Expect. 2015:18(6):2266-77.

15. Baatenburg de Jong RJ, Hermans J, Molenaar J, Briaire JJ, le Cessie S. Prediction of survival in patients with head and neck cancer. Head Neck. 2001;23(9):718-24.

16. Datema FR, Ferrier MB, van der Schroeff MP, Baatenburg de Jong RJ. Impact of comorbidity on short-term mortality and overall survival of head and neck cancer patients. Head Neck. 2010;32(6):728-36.

17. Datema FR, Ferrier MB, Vergouwe Y, Moya A, Molenaar J, Piccirillo JF, et al. Update and external validation of a head and neck cancer prognostic model. Head Neck. 2013:35(9):1232-7.

18. Steyerberg EW, Moons KG, van der Windt DA, Hayden JA, Perel P, Schroter $S$, et al. Prognosis research strategy (PROGRESS) 3: prognostic model research. PLoS Med. 2013;10(2):e1001381. 
19. Han PK, Lehman TC, Massett H, Lee SJ, Klein WM, Freedman AN. Conceptual problems in laypersons' understanding of individualized cancer risk: a qualitative study. Health Expect. 2009;12(1):4-17.

20. Tong A, Sainsbury P, Craig J. Consolidated criteria for reporting qualitative research (COREQ): a 32-item checklist for interviews and focus groups. Int J Qual Health Care. 2007;19(6):349-57.

21. Suls J, Wheeler L. Handbook of social comparison: theory and research: Springer Science \& Business Media; 2013.

22. Creswell JW, Poth CN. Qualitative inquiry and research design: choosing among five approaches: sage publications; 2016.

23. Statistiek CBvd. Standaard onderwijsindeling. 2016.

24. Isced U. International standard classification of education. United Nations Educational, Scientific and Cultural Organization (UNESCO); 2011.

25. : Netherlands Comprehensive Cancer Organisation (IKNL); [Available from: http://www.cijfersoverkanker.nl. Accessed 1 Jan 2020.

26. Kaplowitz SA, Campo S, Chiu WT. Cancer patients' desires for communication of prognosis information. Health Commun. 2002;14(2):221-41.

27. Clayton JM, Butow PN, Arnold RM, Tattersall MH. Discussing life expectancy with terminally ill cancer patients and their carers: a qualitative study. Support Care Cancer. 2005;13(9):733-42.

28. Friedrichsen MJ, Strang PM, Carlsson ME. Cancer patients' interpretations of verbal expressions when given information about ending cancer treatment. Palliat Med. 2002;16(4):323-30.

29. Fried TR, Bradley EH, O'Leary J. Prognosis communication in serious illness: perceptions of older patients, caregivers, and clinicians. J Am Geriatr Soc. 2003;51(10):1398-403.

30. Gabrijel S, Grize L, Helfenstein E, Brutsche M, Grossman P, Tamm M, et al. Receiving the diagnosis of lung cancer: patient recall of information and satisfaction with physician communication. J Clin Oncol. 2008;26(2):297-302.

31. Fried TR, Bradley EH, Towle VR, Allore H. Understanding the treatment preferences of seriously ill patients. N Engl J Med. 2002;346(14):1061-6.

32. Blanchard P, Volk RJ, Ringash J, Peterson SK, Hutcheson KA, Frank SJ. Assessing head and neck cancer patient preferences and expectations: a systematic review. Oral Oncol. 2016;62:44-53.

33. Innes S, Payne S. Advanced cancer patients' prognostic information preferences: a review. Palliat Med. 2009;23(1):29-39.

34. Clayton JM, Butow PN, Tattersall MH. When and how to initiate discussion about prognosis and end-of-life issues with terminally ill patients. J Pain Symptom Manag. 2005;30(2):132-44.

35. Kutner JS, Steiner JF, Corbett KK, Jahnigen DW, Barton PL. Information needs in terminal illness. Soc Sci Med. 1999;48(10):1341-52.

36. Kirk P, Kirk I, Kristjanson LJ. What do patients receiving palliative care for cancer and their families want to be told? A Canadian and Australian qualitative study. BMJ. 2004;328(7452):1343.

37. Clayton JM, Butow PN, Arnold RM, Tattersall MH. Fostering coping and nurturing hope when discussing the future with terminally ill cancer patients and their caregivers. Cancer. 2005;103(9):1965-75.

38. Clayton JM, Hancock K, Parker S, Butow PN, Walder S, Carrick S, et al, Sustaining hope when communicating with terminally ill patients and their families: a systematic review. Psychooncology. 2008;17(7):641-59.

39. Gordon EJ, Daugherty CK. Hitting you over the head': oncologists' disclosure of prognosis to advanced cancer patients. Bioethics. 2003;17(2):142-68.

40. Feldman-Stewart D, Kocovski N, McConnell BA, Brundage MD, Mackillop WJ. Perception of quantitative information for treatment decisions. Med Decis Mak. 2000;20(2):228-38.

41. Davey HM, Butow PN, Armstrong BK. Cancer patients' preferences for written prognostic information provided outside the clinical context. $\mathrm{Br}$ J Cancer. 2003;89(8):1450-6.

42. Lobb EA, Kenny DT, Butow PN, Tattersall MH. Women's preferences for discussion of prognosis in early breast cancer. Health Expect. 2001;4(1):48-57.

43. Engelhardt EG, Pieterse AH, Han PK, van Duijn-Bakker N, Cluitmans F,

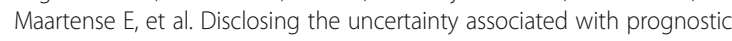
estimates in breast Cancer. Med Decis Mak. 2017;37(3):179-92.

44. Politi MC, Han PK, Col NF. Communicating the uncertainty of harms and benefits of medical interventions. Med Decis Mak. 2007;27(5):681-95.

45. Clayton JM, Butow PN, Tattersall MH. The needs of terminally ill cancer patients versus those of caregivers for information regarding prognosis and end-of-life issues. Cancer. 2005;103(9):1957-64.

46. Pulte $\mathrm{D}$, Brenner $\mathrm{H}$. Changes in survival in head and neck cancers in the late 20th and early 21st century: a period analysis. Oncologist. 2010;15(9):994-1001.

\section{Publisher's Note}

Springer Nature remains neutral with regard to jurisdictional claims in published maps and institutional affiliations.

\section{Ready to submit your research? Choose BMC and benefit from:}

- fast, convenient online submission

- thorough peer review by experienced researchers in your field

- rapid publication on acceptance

- support for research data, including large and complex data types

- gold Open Access which fosters wider collaboration and increased citations

- maximum visibility for your research: over $100 \mathrm{M}$ website views per year

At BMC, research is always in progress.

Learn more biomedcentral.com/submissions 